\title{
GENDER EQUALITY IN SPORT LEADERSHIP: FROM THE BRIGHTON DECLARATION TO THE SYDNEY SCOREBOARD
}

\author{
Johanna A. Adriaanse, University of Technology Sydney and \\ Inge Claringbould, University of Utrecht
}

International Review for the Sociology of Sport, accepted 1 September 2014

\begin{abstract}
This study investigated the development of the legacies of the five World Conferences on Women and Sport that have been auspiced by the International Working Group on Women and Sport from 1994 to 2010. In particular, it examined the ways in which gender is constructed in these legacies in relation to gender equality in sport leadership. The theoretical framework was drawn from Connell’s four-dimensional gender model, which suggests that gender relations can be characterized in terms of four interwoven dimensions of social life: production, power, emotion and symbolism. The method used was a comparative case study of five legacies. We conducted a content analysis of documents relevant to the five legacies. Findings show that, in all five legacies, gender in relation to sport leadership was mainly constructed on the dimension of production and power relations (more women in leadership positions) and symbolic relations (creating a sporting culture that values women's participation at all levels). By contrast, the gendered dimension of emotional relations-collaboration between men and women-received limited attention. The implications of these findings for the acceleration of gender equality in sport leadership are discussed.
\end{abstract}

Keywords: sport leadership, gender, Connell’s gender model, conference legacies, international women's sport movement 
The International Working Group on Women and Sport (IWG) was established in 1994 to increase the involvement of women in sport at all levels, including in decisionmaking and leadership roles. It noted that, although women's participation in sport had increased both at grassroots level and in relation to opportunities to compete at an elite level, women’s representation in sport leadership remained a serious challenge (International Working Group on Women and Sport, 1994). The focus was specifically on high (national and international) level sport leadership positions in management, coaching and officiating. The IWG has auspiced five World Conferences on Women and Sport over the past two decades. Each conference has left a legacy, in the form of declarations, calls for action and other initiatives designed to achieve gender equality in sport including in sport leadership. The legacies aim to contribute to gender equality in sport through influencing sport organizations by providing guidance for policy and practice. This paper examines the development of these legacies with reference to sport leadership. In particular, it explores the way in which they conceptualize gender and to what extent the concept or construction of gender has changed in the legacies over time.

The first legacy was the Brighton Declaration, an outcome of the first World Conference on Women and Sport held in Brighton, UK, in 1994. The aim of this and subsequent conference legacies was to accelerate change in sporting culture, including gender equality in sport leadership. In 2014, participants will gather in Helsinki to celebrate its $20^{\text {th }}$ anniversary at the sixth World Conference on Women and Sport. Other initiatives developed as legacies of the quadrennial World Conferences are the Windhoek Call for Action (1998), the Montreal Toolkit (2002), the Kumamoto Commitment to Collaboration (2006), and the Sydney Scoreboard (2010).

Central to the argument for increasing women’s representation in decision-making positions in sport is the assumption that women represent stakeholders who should be 
included (democratic principle) and that their inclusion increases the pool of talent available for selection into leadership positions (business principle) (Branson, 2007; Erhardt et al., 2003; Huse and Solberg, 2006; Nielsen and Huse, 2010; Singh and Vinnicombe, 2004; van der Walt and Ingley, 2003). A comprehensive review of research on women directors on corporate boards, based on more than 400 publications over the past 30 years (Terjesen et al., 2009), found that corporate governance was improved when women were appointed to boards because they brought "value-adding” talents and represented stakeholders who had previously been excluded. Terjesen and her colleagues (2009) explain that gender diversity on boards contribute to more effective corporate governance in two ways: through individual interactions and through a variety of board processes. They provide evidence that women's presence in the boardroom lead to more sensitivity to other perspectives. Women brought unique skills, knowledge and experience to the board, adding a different voice to debates and decision making. They also frequently asked questions which enhanced the board's independence. Further, they found that boards with three or more women were "significantly more active in promoting non-financial performance measures such as customer and employee satisfaction... as well as considering measures of innovation and corporate social responsibility” (Terjesen et al., 2009: 329).

A growing number of studies seeks to understand the relationship between gender and sport leadership, in particular the issue of women's under-representation in sport management. Researchers have examined this issue in a range of countries, including Australia (McKay, 1992; McKay, 1997; Sibson, 2010; Adriaanse and Schofield, 2013), Canada (Shaw and Slack, 2002; Hall et al., 1989; Inglis, 1997), Germany (Pfister and Radtke, 2009; Doll-Tepper et al., 2006), the Netherlands (Claringbould and Knoppers, 2007; Claringbould and Knoppers, 2008; Claringbould and Knoppers, 2012), New Zealand (Shaw, 2006; Cameron, 1996), Norway (Fasting, 2000; Hovden, 2000; Skirstad, 2002; Hovden, 
2006; Skirstad, 2009; Hovden, 2010), the UK (White and Brackenridge, 1985; Shaw and Penney, 2003; Shaw and Hoeber, 2003) and the USA (Burton et al., 2011; Schull et al., 2013). At an international level, Henry and his colleagues (Henry et al., 2004; Henry and Robinson, 2010) have investigated women’s leadership in the Olympic Movement. Most of the early studies explored questions of exclusion, such as the ratio of women directors and barriers to women obtaining leadership positions, and suggested ameliorative strategies. More recently, researchers have shifted focus by applying a relational gender perspective to investigations of how gender works in sport leadership. In a comprehensive review of research, Burton (2014) has provided a multilevel examination of available scholarship into the area of women's under-representation in sport leadership. It is evident that to date, no study has analysed the development of international initiatives on gender equality and sport leadership as a legacy of the World Conferences on Women and Sport. These legacies aim to contribute to bringing about positive change for gender equality through policy and practice advice.

In this paper, we investigate the context of each World Conference and its legacy in relation to gender equality and sport leadership from 1994 to 2010. Specifically, we examine the construction of gender in the legacies and the way in which this has changed over time. The research questions that informed the study were: 1) How are gender and gender equality constructed in each of the five World Conferences legacies? 2) To what extent has the construction of gender and gender equality changed in these legacies? 3) In light of the study's results, what are the implications for accelerating gender equality in sport leadership? The theoretical framework for the study is Connell's (2009) four-dimensional gender model. Connell contends that the key to understanding gender is to move away from a focus on gender differences to one on relationships between and among men and women at a number of levels, including the personal and institutional. Gender relations are characterized 
by four interwoven dimensions of social life: production, power, emotion and symbolism. Using this model, we provide a deeper and more systematic analysis of how gender and gender equality are constructed in the World Conference legacies in relation to leadership. This approach is a marked departure from previous studies on women's under-representation in sport management and contributes to the field by providing a better understanding of the relationship between gender equality and sport leadership.

This paper is structured in the following way. We first clarify the concepts of sport leadership, gender equality and gendered power. We then present the theoretical framework, Connell’s (2009) four-dimensional gender model, and describe the study’s methodology. The context and legacies of the five World Conferences on Women and Sport, including an overview of relevant international human rights and gender equality instruments, are described and analysed. We draw conclusions about the construction of gender and gender equality in the legacies with reference to sport leadership and discuss implications for practice.

\section{Conceptual Framework: Connell’s Four-Dimensional Gender Model}

Sport leadership refers to people in decision-making positions in the realm of sport. They include executives in sport administration, management and governance as well as coaches and officials. This definition of sport leadership corresponds with the way the term is understood in the Brighton Declaration, one of the objects of this study (International Working Group on Women and Sport, 1994).

Gender equality is the term used in international public policy to refer to equal rights, responsibilities and opportunities of women and men at all levels across a wide range of arenas (United Nations Division for the Advancement of Women, 2007). In this study, we use the term "gender equality” rather than "gender equity”. This is consistent with UN convention and with the theoretical framework on which the study is based. Although the 
two terms originally differed—gender equality typically referred to men and women having equal opportunity with the same rights and resources, while gender equity emphasised fairness and justice for men and women-in current usage, the terms are interchangeable.

The notion of power is central to the topic of gender equality. This core concept has been widely discussed in the social sciences by acclaimed international scholars, such as the French philosopher Michel Foucault (1982) and sociologist Pierre Bourdieu (1977), German sociologist Jurgen Habermas (1976) and the British political theorist Stephen Lukes (1974), among others. The most common interpretation of power is that it is the exercise by an actor or actors of their own will in social practice, even against the resistance of others (Clegg et al., 2011). The actor can be an individual or collective entity such as a group or organization. Regarding the relationship between power, organizations and gender, internationally acclaimed scholar Kanter (1977) argued that the role of managers is profoundly masculinised since rationality and efficiency are the raison d'être for their position. She concluded that it was the structure of the corporation rather than individual characteristics that caused gender inequalities. Problems for women arose because they were located in dead-end jobs at the bottom of the organization or appeared as tokens at the top.

Building on this perspective, Acker (1990) introduced the concept of the 'gendered organization'. She argued that organizations are not gender-neutral and should be viewed as sites that are gender-patterned in their very constitution. That is, their basic components—structure, ideology, policy and practice, interaction and identity-are characterized by a distinction between male and female, masculine and feminine. This constitutive patterning, according to Acker, simultaneously reproduces gender inequalities, since the distinction that characterizes it necessarily involves hierarchical differentiation of values along gendered lines. 
Much of the recent theoretical work on gender builds on the concept of gender as a verb—we 'do gender' on a routine, daily basis (West and Zimmerman, 1987; Connell, 1987). This approach has also been explored by European scholars, most notably in Kvande’s (2007) work on gender and organizations. Integrating the approaches of Connell (1987), West and Zimmerman (1987), West and Fenstermaker (1995), and Acker (1990), she proposed that gender is dynamic and flexible since it is constantly created and accomplished in response to the social environment. In contrast to the view of gender as something that is inherited and/or comprised of learned individual qualities, Kvande emphasized its dynamic interactive nature. She suggested that the 'doing gender’ perspective allows us to identify patterns of gendered practices that are created not only by individuals but also, importantly, by corporations and organizations.

Connell (2009) has provided a contemporary framework for identifying a pattern of gendered practices, based on four main areas of social life. The combination of these four dimensions, and the pattern of gender relations produced by it, is what Connell (2009) calls a “gender regime” (Connell, 2009: 72).

The first dimension of the gender model is production relations or the gendered division of labor, which refers to the way in which production or work is arranged along gender lines. In the context of sport organizations, this gender division relates to the roles and tasks allocated to men and women in the organization, including at the executive level.

The second dimension of the gender model is gender relations of power, that is, the way in which control, authority, and force are exercised, individually and collectively, along gender lines, including organizational hierarchy, legal power and violence. When applied to sport organizations, this dimension usually refers to men's dominance and influence in decision-making and how they advance their interests in the process. 
The third dimension is emotion and human relations, that is, the way attachment and antagonism among people and groups are organized along gender lines, including feelings of solidarity, prejudice, sexual attraction and repulsion. Emotional relations in sport organizations relate to the patterns of attachment and hostility that exist within and between men and women and include, for example, the ways they support and collaborate or oppose and undermine each other in their work.

The fourth dimension is gender culture and symbolism, that is, the way in which gender identities are defined and gender is represented and understood, including prevailing beliefs and attitudes about gender. In reference to sport organizations, symbolic relations are operationalized in their understanding of gender and gender equality, including beliefs about gender parity in leadership positions and gender equality in governance. Although these four structures of gender relations can be distinguished, they do not operate independently but are interwoven and constantly interact with each other.

Connell (2005) and Schofield and Goodwin (2005) have effectively applied the fourdimensional gender model to the analyses of gender dynamics in several public sector institutions in Australia. In the realm of sport, their approach has been adopted in an investigation of the gender relations that characterize the composition and operation of boards of Australian National Sport Organisations (NSOs) and the extent to which they offer opportunities for, or pose barriers to, gender equal governance (Adriaanse and Schofield, 2013; Adriaanse, 2013). The present study builds on these studies by using the model to analyse the construction of gender in the World Conference legacies from 1994 to 2010.

\section{Method}

The research design comprised a comparative case study of the five legacies from the World Conferences on Women and Sport (1994-2010). We collected a range of documents, starting with those that outlined each legacy of the five World Conferences, namely, the 
Brighton Declaration, the Windhoek Call for Action, the Montreal Toolkit, the Kumamoto Commitment to Collaboration and the Sydney Scoreboard. For each legacy, we identified the sections that referred to gender equality in sport leadership.

We also collected documentation of relevant instruments developed by the UN which had informed the conference legacies. These included the Millennium Development Goals, the Universal Declaration of Human Rights and the Convention on the Elimination of All Forms of Discrimination against Women (CEDAW). In order to gain a better understanding of the wider context of the conference legacies, we identified those sections of the UN instruments that focused on gender equality, sport and/or leadership.

In addition, we collected data from documents relating to IWG Annual Meetings, Conference Programs, IWG Workshops and other papers and notes from the IWG Secretariat. These documents are publicly available at the University of Chichester, which holds the archives of the international women and sport movement.

Our main analytical strategy was informed by the conceptual framework, as recommended for case study research (Yin, 2009). The four dimensions of Connell's (2009) gender model provided the a priori concepts for data analysis. Each legacy was read to identify and code any sections that were relevant to a particular category of Connell's framework of gender relations. Similar to Adriaanse and Schofield's study (2013), Connell's model was adapted to work as a data analysis tool by formulating the four dimensions as questions to be applied to the data. The first category, production relations, was operationalized by becoming the question, how does the legacy address the roles and tasks on the board of sport organizations in terms of men and women? The second category, power relations, became the question, how does the legacy address issues of influence, authority and control in terms of men and women directors? The third category, emotional relations, was applied to the data analysis as, how does the legacy address human relationships between and 
among men and women directors? The final category, symbolic relations, was addressed through the question, how does the legacy address cultural and symbolic understandings of gender and gender equality?

Thus, the procedure involved identifying which dimensions were addressed in each conference legacy. A separate file was compiled for each legacy containing a separate section for each category or code. After identifying the gender dimensions for each legacy, we conducted a cross case synthesis (Yin, 2009).

\section{Results}

This section begins with an overview of those UN instruments that informed the conference legacies. Subsequently, we describe the context in which each legacy was conceptualized and explain the actual legacy, with particular focus on the section that relates to sport leadership. Applying the four-dimensional gender model, we then systematically analyze which dimensions are addressed in each legacy.

\section{International human rights, gender equality and sport}

In 2000, international leaders gathered to develop a vision for a better world that would be characterized by less poverty, better-educated children and a sustainable environment. Their vision was captured in the United Nations' eight Millennium Development Goals, a framework for development with a target date of 2015 (United Nations, 2011). One of these goals, the third Millennium Development Goal, is "to promote gender equality and empower women” (United Nations, 2011: 1). It is noteworthy that this goal mentions gender equality in combination with the empowerment of women, which is consistent with the notion that gender equality involves women as active agents in empowering their own experiences.

The concept of gender equality has been on the global development agenda since the inception of the United Nations in 1945. Calls for gender equality were already documented 
in the Charter of the United Nations (United Nations, 1945) and the Universal Declaration of Human Rights (United Nations, 1948). The following articles in the Universal Declaration are relevant to the realm of sport and physical education: "Everyone has the right to rest and leisure...” (article 24) (United Nations, 1948: 1); “Education shall be directed to the full development of the human personality...” (article 26) (United Nations, 1948: 1); and, on the assumption that sport is an integral part of cultural life, "Everyone has the right to freely participate in the cultural life of the community...” (article 27) (United Nations, 1948: 1).

When the UN Convention on the Elimination of all Forms of Discrimination Against Women (CEDAW) was adopted more than 30 years later, further calls were made to promote women’s and girls’ involvement in sport (United Nations, 1979). Article 10 asks participating nations to take measures to eliminate discrimination against women and girls in the field of education in order to ensure that they have the same opportunities as men and boys, including active participation in sport and physical education. In addition, article 13 calls on participating nations to take measures to eliminate discrimination against women in other areas of economic and social life in order to ensure that women have the same rights as men to participate in recreational activities, sports and all aspects of cultural life (United Nations, 1979).

Other international instruments related to improving the lives of women and girls include the Ottawa Charter (World Health Organisation, 1986) and the Beijing Declaration and the Platform for Action Fourth World Conference on Women (United Nations, 1995). The latter, adopted at the Fourth World Conference on Women in Beijing in 1995, provides several policy recommendations on women, gender equality and sport, including calls for women to fill sport leadership positions. In the critical area of education, The Beijing Platform for Action calls for governments and educational institutions to establish gendersensitive programs to support the advancement of women of all ages in sport and physical 
activity, including administration and coaching at national, regional and international levels. Further, in the critical area of power and decision-making, it notes that the underrepresentation of women in leadership positions in culture, sport, education and law has prevented women from having a significant impact on many key institutions (United Nations, 1995).

\section{The Brighton Declaration}

In response to the UN instruments, the first international sport-related declaration in relation to gender equality was developed in 1994. Known as the Brighton Declaration (International Working Group on Women and Sport, 1994), it was the legacy of the First World Conference on Women and Sport held in Brighton, United Kingdom. This conference, entitled “Challenge of Change”, reflected a shift in the women’s sport movement towards its inclusion in a wider feminist and political agenda. The conference, targeted at sport policy and decision-makers at national and international levels, aimed to accelerate the process of change towards a more equitable global sporting culture. A conscious effort was made to include women from developing countries and all regions of the world. Substantial support and funding were secured from the (then) UK Sports Council, British Council and the International Olympic Committee (IOC). Representing a global voice, 280 delegates from 82 countries attended the conference and endorsed the Brighton Declaration. Informed by the Charter of the United Nations (United Nations, 1945), the Universal Declaration of Human Rights (United Nations, 1948) and the UN Convention on the Elimination of all Forms of Discrimination Against Women (CEDAW) (United Nations, 1979), the Brighton Declaration's main aim was “to develop a sporting culture that enables and values the full involvement of women in every aspect of sport” (International Working Group on Women and Sport, 1994: 1). 
The Brighton Declaration is a four-page document which starts with a brief overview of the First World Conference on Women and Sport and background to the Declaration. It then presents the actual Declaration which contains ten guiding principles relating to equality in society and sport: facilities, school and junior sport, developing participation, high performance sport, leadership in sport, education, training and development, sports information and research, resources, and domestic and international cooperation. Two sections specifically refer to sport leadership. The first section is found in the background to the Brighton Declaration and states:

Despite growing participation of women in sport in recent years and increased opportunities for women to participate in domestic and international arenas, increased representation of women in decision making and leadership roles within sport has not followed. Women are significantly under-represented in management, coaching and officiating, particularly at the higher levels. Without women leaders, decision makers and role models within sport, equal opportunities for women and girls will not be achieved (International Working Group on Women and Sport, 1994: 1).

The second section comprises the principle in regard to leadership in sport which says: Women are under-represented in the leadership and decision making of all sport and sport-related organisations. Those responsible for these areas should develop policies and programs and design structures which increase the number of women coaches, advisers, decision makers, officials, administrators and sports personnel at all levels with special attention given to recruitment, development and retention (International Working Group on Women and Sport, 1994: 2).

Thus, it recommended that people in powerful positions create opportunities for women to obtain leadership positions in sport organizations. 
Applying Connell’s four-dimensional gender model, the Brighton Declaration clearly addresses the symbolic dimension of gender because it emphasizes beliefs, values, culture and principles. It puts gender equality on the political agenda and seeks to change the sporting culture. The strong connection to UN instruments and human rights is evident in the first principle of the Declaration which states:

Every effort should be made by state and government machineries to ensure that institutions and organizations responsible for sport comply with the equality provisions of the Charter of the United Nations, the Universal Declaration of Human Rights and the UN Convention on the Elimination of All Forms of Discrimination against Women (International Working Group on Women and Sport, 1994: 2).

This citation demonstrates the Brighton Declaration's relevance to the symbolic dimension of gender relations. For example, article 27 in the Universal Declaration of Human Rights states that everyone (i.e. including women) has the right to freely participate in the cultural life of the community, including sport. This is a clear statement of values around gender relations and gender equality.

Further, the Brighton Declaration addresses the production and power dimensions of Connell's gender model which as previously outlined, relate to the number, roles and tasks of men and women. The leadership principle emphasizes "increase(ing) the number of women coaches, advisers, decision makers, officials, administrators” (International Working Group on Women and Sport, 1994: 2). This is a call for a shift in sport leadership positions, with more roles and tasks allocated to women who, through their increased presence, will have more power, authority and influence in decision-making.

There is, however, no explicit statement in the Brighton Declaration that refers to the emotional dimension of gender relations. Although it urges those responsible in sport 
organizations to create opportunities for women to obtain leadership positions, it does not explicitly identify men, who hold most of the influential positions, as those who must assume responsibility for taking such supportive action. It does not refer to men’s and women's collaboration and solidarity.

\section{The Windhoek Call for Action}

The International Working Group on Women and Sport (IWG) was established at the conclusion of the First World Conference on Women and Sport. This was a global coordination network with close links to national governments and key non-government organizations (Hargreaves, 2000). The main purpose of the IWG was to monitor the implementation of the Brighton Declaration and to plan future World Conferences on Women and Sport. Four years later, in 1998, the Second World Conference on Women and Sport was held in Windhoek, Namibia, with the theme "Reaching out for Change". A total of 400 delegates from 74 countries adopted the Windhoek Call for Action (International Working Group on Women and Sport, 1998), the legacy of the conference. This two-page document starts, similar to the Brighton Declaration, with a brief overview of the most recent World Conference on Women and Sport and background. Subsequently it calls for action in several areas.

In the background section it notes the need to establish connections with existing UN international instruments, including those which resulted from the Fourth World Conference on Women in Beijing in 1995. This again reflects a conscious effort by the IWG to locate the advancement of women and sport within the broader global women's movement and to emphasize the positive contribution of girls' and women's involvement in sport to social, health and economic aspects of life. The Windhoek Call for Action reaffirmed the principles of the Brighton Declaration. In addition, it called for action in eleven areas, including the area of leadership: 
Build the capacity of women as leaders and decision makers and ensure that women play meaningful and visible roles in sport at all levels. Create mechanisms that ensure that young women have a voice in the development of policies and programmes that affect them (International Working Group on Women and Sport, 1998: 1).

The emphasis on building women's capacity as leaders and including the voices of young women in policy making and programming are noteworthy.

In terms of the four-dimensional gender model, the Windhoek Call for Action addresses the symbolic dimension since it is informed by (then) recently developed UN instruments. It states: “...the need for linkages into existing international instruments, in particular the Beijing Platform for Action and the UN Convention on the Elimination of All Forms of Discrimination against Women (International Working Group on Women and Sport, 1998: 1). Considering that these instruments focus on beliefs, values and principles regarding gender and gender equality it is evident that this legacy refers to the symbolic dimension of gender.

Further, the emphasis on capacity-building and on ensuring that women "play meaningful and visible roles in sport at all levels” (International Working Group on Women and Sport, 1998: 1) show that this legacy involves production relations, the division of labour along gender lines. The statement about women "hav(ing) a voice in the development of policies and programmes” (International Working Group on Women and Sport, 1998: 1), thereby exerting influence and control, relates to the power dimension of gender relations.

Emotional relations are referenced in several ways. The conference theme of "Reaching Out" and the choice of conference location (Africa) reflect an emphasis on engaging more women internationally. The focus on diversity, which was not confined to geographical location, was further evidenced in another statement in the Windhoek Call for Action that highlighted the need for sport policies and programs to provide opportunities for 
all women regardless of race, ethnicity, ability, religion, culture, sexual orientation and status as an indigenous person (International Working Group on Women and Sport, 1998). These aspects of women's diversity and inclusiveness suggest support, solidarity and collaboration among women. On the other hand, as with the previous legacy, it does not explicitly propose support and collaboration between women and men. Therefore, this legacy explicitly addresses the emotional dimension of gender between women only.

\section{The Montreal Toolkit}

The issue of women in leadership positions remained at the forefront during the Third World Conference on Women and Sport held in Montreal, Canada, in 2002. The conference theme was "Investing in Change" and 550 participants from 97 countries endorsed its legacy, the Montreal Tool Kit (International Working Group on Women and Sport, 2002). This initiative contained 20 tools - 70 pages of materials and ideas - for conference participants to implement in their own country and situation to increase women's and girls' opportunities in sport. It was based on successful strategies generated by women and men around the world to advance women's participation and leadership in sport. Amongst other materials, it provided several strategies and practical ideas to increase the number of women in decision-making positions across four sections, namely, tools for advocating change, for changing organizations, for individual development and for preparing an action plan (International Working Group on Women and Sport, 2002).

In relation to the four-dimensional gender model, this legacy, which is mainly a practical resource, involves both production and power relations because of its focus on increasing the number of women in decision-making positions (i.e. sport leadership). For example, the first tool in the section on advocating change suggests using facts and stats to highlight "why girls and women should have more opportunities to participate and lead (our emphasis) in sport and physical activity” (International Working Group on Women and 
Sport, 2002: 1). In addition, one of the tools in the section on changing organizations, systems and structures outlines steps for the development of a national policy that includes "increasing the number of women and girls in key-decision making and leadership positions in sport, recreation and physical activity” (International Working Group on Women and Sport, 2002: 29). Further, in the section on tools for individual development, the focus of tool 18 is on recruiting and retaining women in leadership roles of coaching and officiating. This tool outlines objectives and strategies "as a guide to involving more women in coaching and officiating roles” (International Working Group on Women and Sport, 2002: 52).

The symbolic dimension of the gender model is also addressed: as the preface of the Montreal Toolkit explains, the strategies and tools are designed to bring about "exciting changes resulting in fairer opportunities for girls and women in sport and physical activity” (International Working Group on Women and Sport, 2002: iv). It is about changing the culture of sport towards gender equality which involves beliefs, values and principles and therefore relates to the symbolic dimension.

None of the 20 tools described in the toolkit, however, specifically aims to enhance collaboration between men and women or gain support from men to effect change. Tool four entitled Building coalitions and partnerships in which one could expect a suggestion of partnership between men and women fails to mention it. For example, this tool states “involve more people...in accomplishing common goals” and promote “ shared leadership” (International Working Group on Women and Sport, 2002: 12) which may imply but does not explicitly express collaboration with men. Therefore, the emotional dimension of gender relations with reference to collaboration between men and women has not explicitly been addressed in this legacy. 


\section{The Kumamoto Commitment to Collaboration}

In 2006, 700 participants from 74 countries gathered for the Fourth World Conference on Women and Sport in Kumamoto, Japan, under the theme "Participating in Change". It was the first time the World Conference had been held in Asia. The program comprised, in addition to plenary sessions, twelve workshops designed to be interactive leading to recommendations supported by the participants. As documented in the conference program, Dr. Anita White, Conference Program Coordinator, outlined that "The outcomes of the workshops, together with recommendations made by speakers, will all contribute to a future vision for women and sport to be articulated in the plenary session on the last day of the conference” (International Working Group on Women and Sport, 2006b). An important part of the future vision was the legacy of this conference: The Kumamoto Commitment to Collaboration, a graphic display unveiled on the final conference day. According to one description that attempts to capture its meaning:

In order to realize gender equality in and through sport, we commit to building a network for close collaboration with relevant agencies and individuals. Over the next four years (2006-2010), we will further develop the vision of active participation in change born at the Kumamoto Conference (International Working Group on Women and Sport, 2006a: 1).

The notion of collaboration evolved from the fact that, since the Brighton Declaration, a plethora of women's sport organizations had emerged at local, national and regional level. In order to effectively progress the women's sport movement, there was a need to collaborate, share and learn from each other and build on each other's efforts.

Participants at this World Conference engaged in a series of workshops, one of which was called "Changing the Culture of Leadership in Sport”. This workshop resulted in several recommendations for action, including: 
- Conduct more research and case studies reflecting women's positions and leadership;

- Replicate research in each country about women’s leadership and position on National Sport Organizations; and

- Work within UN structures to promote access to women's sport leadership opportunities

(International Working Group on Women and Sport, 2006c).

Minutes of the IWG Annual General Meeting in May 2006 reiterate the final recommendation by stating that a decision was made to strengthen the relationship with UN agencies in future years, including through IWG's representation at annual meetings (Commission on the Status of Women) organized by the UN Division for the Advancement for Women in New York.

In relation to the four-dimensional gender model, this legacy appears at first sight to represent a unique approach. It seems markedly different from the previous legacies insofar as it places emphasis on the role of emotional and human relations in achieving gender equality which is evident in its call for "building a network for close collaboration with relevant organizations and individuals” (International Working Group on Women and Sport, 2006a: 1). Closer analysis, however, shows that the Kumamoto Commitment to Collaboration does not specify collaboration or support along gender lines, that is, between men and women.

As in the earlier legacies, production, power and symbolic gender relations were all addressed in the broader context of the Kumamoto Conference, as evidenced by the recommendations of the workshop on leadership in sport. The recommendations for conducting and replicating research on women's representation in leadership positions refer 
to both production and power relations. The recommendation on liaison with UN structures refers to the UN declarations and conventions, which include principles, rights and values, and therefore involves the symbolic dimension of gender relations.

\section{The Sydney Scoreboard}

Following the recommendation of the Kumamoto Conference, researchers from the IWG and WomenSport International collaborated with the United Nations Division for the Advancement of Women (UNDAW) on a major publication on women and sport and the effectiveness of sport in promoting equality and social development. The Director of UNDAW, Carolyn Hannan (2006), argued that sport and physical activity are powerful tools for women’s and girls' development. The resulting publication, Women 2000 and Beyond: Women, Gender Equality and Sport, was launched during the $52^{\text {nd }}$ Session of the Commission on the Status of Women at the UN Headquarters in New York in 2008. This monograph was part of the Women 2000 and Beyond series which promotes the goals of the Beijing Declaration and the Platform for Action. It was the first time in the history of the United Nations that a full publication was dedicated to women and sport. Amongst other issues, it identified the under-representation of women in decision-making bodies of sport organizations at local, national, regional and international levels as a major area of concern (United Nations Division for the Advancement of Women, 2007). In order to accelerate the process of change in sport governance it recommended:

[going] beyond increasing numbers to enhancing the effectiveness and impact of women's participation, through increasing women’s voice in shaping policies, resource allocations, and program development and management...Monitoring and evaluation of the impact of initiatives, such as the use of targets and quotas, need to be significantly strengthened. Reliable and comparable data are required, both as an 
advocacy and awareness tool (United Nations Division for the Advancement of Women, 2007: 29-30).

The issue of women in sport governance was revisited at the Fifth World Conference on Women and Sport held in Sydney in 2010, which attracted 500 participants from 60 countries. The theme of the conference was "Play Think Change", which reflected a clear shift in its approach. Previous World Conferences were mainly targeted at policy and decision-makers in sport, but this time both practitioners (Play) and researchers (Think) were brought together to discuss progress in the global women's sport movement and ways to address the challenges ahead (Change). According to IWG Co-chair Johanna Adriaanse as documented in the conference program:

Reflecting the theme Play | Think | Change the Conference program has been designed to attract both practitioners and researchers from around the globe providing a unique blend of presentations about good practices and cutting-edge research to stimulate debate and explore positive change for women and sport (Adriaanse et al., 2010).

It was agreed that the legacy of this conference was the Sydney Scoreboard, the purpose of which was to increase:

[w]ithin the context of the achievement of the UN Millennium Development Goals...the number of women on the boards/management committees of all sport organisations at international, regional, national and local level (International Working Group on Women and Sport, 2012).

The Sydney Scoreboard, a global index for women in sport leadership, operates as an online tool through which women in leadership roles within sport organizations can be 
tracked both nationally and internationally. This web-based database of 260 pages displays information on the gender distribution on boards of sport organizations globally. Its aim is to provide information for policy and practice and in this way to contribute to achieving gender equality in sport management and governance.

In relation to the four-dimensional model, the notion of gender and gender equality in the Sydney Scoreboard is mainly constructed on the power and production dimensions, since it focuses on increasing the number of women in sport leadership positions. Specifically, this legacy addresses production relations due to its emphasis on more roles for women in leadership. It also involves power relations because, when women assume more leadership roles, they are able to increase their influence and control in sport organizations. Its reference to the UN Millennium Development Goals, a framework of values and principles, shows that this legacy also involves the symbolic dimension of gender relations. Reference to the emotional dimension of gender relations is, however, absent. The legacy makes no mention of men and women working together to achieve a more balanced gender distribution on sport boards and in sport management.

In summary, starting with the Brighton Declaration in 1994, there has been a consistent and sustained call for action and other initiatives to advance gender equality in sport, including sport leadership. This process has taken place at an international level and is based on a human rights perspective. Table 1 provides a summary of the five World Conferences, their legacies and associated gender dimensions. 
Table 1

Gender Dimensions in Legacies of the World Conferences on Women and Sport

\begin{tabular}{|c|c|c|c|c|c|c|}
\hline Year & Location & Legacy & $\begin{array}{l}\text { Production } \\
\text { Relations }\end{array}$ & $\begin{array}{l}\text { Power } \\
\text { Relations }\end{array}$ & $\begin{array}{l}\text { Emotional } \\
\text { Relations }\end{array}$ & $\begin{array}{l}\text { Symbolic } \\
\text { Relations }\end{array}$ \\
\hline 1994 & $\begin{array}{l}\text { Brighton, } \\
\text { UK }\end{array}$ & $\begin{array}{l}\text { Brighton } \\
\text { Declaration }\end{array}$ & $\checkmark$ & $\checkmark$ & - & $\checkmark$ \\
\hline 1998 & $\begin{array}{l}\text { Windhoek, } \\
\text { Namibia }\end{array}$ & $\begin{array}{l}\text { Windhoek } \\
\text { Call for } \\
\text { Action }\end{array}$ & $\checkmark$ & $\checkmark$ & limited & $\checkmark$ \\
\hline 2002 & $\begin{array}{l}\text { Montreal, } \\
\text { Canada }\end{array}$ & $\begin{array}{l}\text { Montreal } \\
\text { Toolkit }\end{array}$ & $\checkmark$ & $\checkmark$ & - & $\checkmark$ \\
\hline 2006 & $\begin{array}{l}\text { Kumamoto, } \\
\text { Japan }\end{array}$ & $\begin{array}{l}\text { Kumamoto } \\
\text { Commitment } \\
\text { to } \\
\text { Collaboration }\end{array}$ & $\checkmark$ & $\checkmark$ & limited & $\checkmark$ \\
\hline 2010 & $\begin{array}{l}\text { Sydney, } \\
\text { Australia }\end{array}$ & $\begin{array}{l}\text { Sydney } \\
\text { Scoreboard }\end{array}$ & $\checkmark$ & $\checkmark$ & - & $\checkmark$ \\
\hline
\end{tabular}

\section{Discussion}

In relation to our first research question, the results allow us to identify the ways in which gender was constructed in each legacy. By applying Connell’s (2009) fourdimensional gender model, we found that the concepts of gender and gender equality in all five legacies were mainly constructed on the dimensions of production, power and symbolic relations. With regard to sport leadership, the focus in all five legacies was on increasing the number of women in leadership positions, which involves production and power relations. Considering that all legacies were firmly based on human rights principles and instruments, were connected to a broader feminist and political agenda, and aimed to change the sporting culture, it is evident that symbolic relations also play a major role in the construction of gender. By contrast, reference to emotional relations in terms of collaboration and support between and among men and women has been limited. Although some legacies have emphasized solidarity and collaboration (e.g. the Windhoek Call for Action and the Kumamoto Commitment to Collaboration), none of the legacies has explicitly alluded to these relations along gender lines - between men and women - in the construction of gender. 
With reference to the second research question, we found that there has been little change in the construction of gender and gender equality in the five legacies. Apart from a relatively strong focus on symbolic relations in the Brighton Declaration and a relatively strong focus on production and power relations in the Sydney Scoreboard, these three dimensions consistently feature in all five legacies. Equally significantly, the dimension of emotional relations between men and women has consistently been ignored.

The limited reference to emotional relations in the construction of gender and gender equality warrants further discussion. A recent study by Adriaanse and Schofield (2013) shows that emotional relations had an impact on gender equality. It investigated gender equality on sport boards of Australian National Sport Organizations using the fourdimensional gender model. The researchers found that all four dimensions-structures of practice-influenced the way gender operates on sport boards. Increasing the number of women on sport boards (production and power relations) was an important first step towards gender equality. However, another key finding was that relations of support and collaboration that existed between men and women on the board impacted on gender equal governance. Hostility by male board members towards women's presence and participation, especially if women hold leadership positions, undermined gender equal governance. Conversely, active endorsement of and support for women by men on boards, particularly if these men hold leadership positions, was highly effective in advancing gender equality. The establishment of relations of solidarity between women and men on boards was vital in progressing gender equality.

The significance of the role of men in advancing or obstructing gender equality in sport leadership has been discussed in a number of studies. For example, several researchers (Radtke, 2006; Sibson, 2010; Shaw, 2006) found that some male board members actively prevented women from gaining or maintaining a seat at the boardroom table. This occurred 
when women were given less opportunity than men to contribute and develop, were excluded from male networks, or through intimidation and/or sexual harassment. Other studies have shown that men can control boards by framing the process of recruitment and selection in such a way that the male-dominated culture on the sport board was maintained (Hovden, 2000; Claringbould and Knoppers, 2007; Hall et al., 1989). This happened when male board members selected women who “fit” to recreate themselves. Hovden's (2000) examination of leadership selection in Norwegian sport organizations found that the selection discourses strongly reflected male-centered images of corporate leadership skills. The term "heavyweight” was used as a metaphor of preferred leadership skills. According to Hovden (2000), these skills were associated with heroic, powerful, masculine characteristics but were perceived as gender neutral. The common strategy of searching networks of friends and colleagues for potential board members recreated the existing gender structure.

Claringbould and Knoppers (2008) introduced a different perspective with their suggestion that men can play a significant role in the "undoing” of gender meanings in behavior or tasks. They examined how board members of national sport organizations in the Netherlands engaged in "doing and undoing gender in sport governance” (Claringbould and Knoppers, 2008: 81). Male directors did gender when they described male and female qualities but undid gender when they allocated stereotypical behaviors in atypical ways-for example, by allocating women the responsibility for high performance sport development or appointing them as chairpersons. The authors emphasized that influential men can become change agents by using their position to bring about change. Claringbould's and Knoppers' approach shifts the focus from the ways in which men can obstruct gender equality to those in which men can advance gender equality in sport governance.

This leads into the third research question. In light of the study's results, what are the implications for accelerating gender equality in sport leadership? Considering the limited 
focus in the legacies on the emotional dimension of gender relations, it is suggested that establishing closer collaboration and support between men and women will advance gender equality in sport leadership. According to Hargreaves (2000), the most significant outcome of the Brighton Conference and Declaration was the provision of a mechanism of empowerment for women to change the sporting culture. Many women who had been working in isolation in their local communities now became part of a global network that inspired and empowered them to work towards a more equitable sporting environment. The establishment of a collaborative network was further emphasized in the Kumamoto Commitment to Collaboration. Although men were not actively excluded, analysis of the legacies showed that they were not explicitly included in this network either. Initially, strengthening the emotional relations between women was an effective strategy for gender equality but now a legacy that explicitly involves men may accelerate gender equality in sport leadership. The importance of pro-actively including men and boys in gender equality processes has been acknowledged in the context of gender politics on a world scale since the 1995 Beijing World Conference on Women (Connell, 2009; United Nations Division for the Advancement of Women, 2008). This is based on the premise that gender equality cannot be achieved by women alone. Men need to be engaged because they often control the resources that are required and, more importantly, because men will also benefit from gender equality.

\section{Conclusion}

Findings of this study show that the construction of gender in all five legacies has mainly centred on social practices associated with production, power and symbolic relations. In relation to sport leadership, the legacies focussed on increasing the number of women in leadership roles (production relations), affording women more influence through their increased presence in decision-making positions (power relations), and creating a sporting culture that enables and values women's participation at all levels (symbolic relations). 
By contrast, the dimension of emotional relations received limited attention.

Although the establishment of a global network has significantly strengthened emotional relations among women themselves, there is no evidence that it has also enhanced solidaristic relations between men and women. None of the five legacies explicitly referred to emotional relations between men and women.

Although we have analyzed the four dimensions separately, in reality they interact and influence each other. If the emotional dimension of gender relations is addressed by, for instance, engaging men to support gender equality in sport leadership, men may allocate more leadership roles to women which, in turn, may lead to an increase in women's authority and influence and, ultimately, to a cultural change in sport. In other words, changing the emotional dimension can affect the other dimensions of production, power and symbolism.

Our findings have clear implications for practice to accelerate gender equality in sport leadership. While the establishment of a collaborative global network for women and sport has inspired and empowered women, a strategy of proactive inclusion of men is also required. Without losing sight of the importance of supportive relationships among women, we recommend that the network be extended to incorporate more men-in particular, influential men who can use their positions to bring about change. Increasing women's representation on sport boards, as previously discussed, contributes to more sensitivity to other perspectives, enhances the board's independence and can lead to more effective governance. Gender equality in sport leadership will benefit women, men and sport organizations.

In light of the findings of the present study, we recommend that future research examines emotional relations and leadership in sport organizations, in particular the role of men, since this area requires further development and understanding. Another recommendation for further research is to investigate the way in which the IWG legacies 
have been implemented in practice including to what extent they have influenced the development of sport policy. 


\section{References}

Acker J. (1990) Hierarchies, jobs, bodies: A theory of gendered organisations. Gender and society 4: 139-158.

Adriaanse JA. (2013) The role of men in advancing gender equality in sport governance. In: Pfister G and Sisjord MK (eds) Gender and sport: Changes and challenges. Munster: Waxmann, 50-70.

Adriaanse JA, Hamer-Smith C and Latour M. (2010) Program and abstract book 5th IWG World Conference on Women and Sport, Sydney: International Working Group on Women and Sport.

Adriaanse JA and Schofield T. (2013) Analysing gender dynamics in sport governance: A new regimes-based approach. Sport Management Review 16: 498-513.

Bourdieu P. (1977) Outline of a theory of practice, Cambridge and New York: Cambridge University Press.

Branson DM. (2007) No seat at the table: How corporate governance and law keep women out of the boardroom, New York: New York University Press.

Burton LJ. (2014) Underrepresentation of women in sport leadership: A review of research. Sport Management Review 15.

Burton LJ, Grappendorf H and Henderson A. (2011) Perceptions of gender in athletic administration: Utilyzing the congruity to examine (potential) prejudice against women. Journal of Sport Management 25: 36-45.

Cameron J. (1996) Trailblazers: Women who manage New Zealand sport, Christchurch, New Zealand: Sports Inclined.

Claringbould I and Knoppers A. (2007) Finding a 'normal' woman: Selection processes for board membership. Sex Roles 56: 495-507.

Claringbould I and Knoppers A. (2008) Doing and undoing gender in sport governance. Sex Roles 58: 81-92.

Claringbould I and Knoppers A. (2012) Paradoxical practices of gender in sport-related organisations. Journal of Sport Management 26: 404-416.

Clegg S, Kornberger M and Pitsis T. (2011) Managing and organizations: an introduction to theory and practice, London: Sage publications.

Connell R. (1987) Gender and power, Sydney: Allen \& Unwin.

Connell R. (2005) Advancing gender reform in large-scale organisations: A new approach for practioners and researchers. Policy and society 24: 5-24.

Connell R. (2009) Gender, Cambridge, UK: Polity.

Doll-Tepper G, Pfister G and Radtke S. (2006) Progress towards leadership: Biographies and career paths of male and female leaders in German Sport Organisations. Koln: Sportverlag Strauss.

Erhardt NL, Werbel JD and Shrader CB. (2003) Board of director diversity and firm financial performance. Corporate governance 11: 102-111.

Fasting K. (2000) Women's role in national and international sport governing bodies. In: Drinkwater BL (ed) Women in sport: Volume XIII of the Encyclopaedia of Sports Medicine. An IOC Medical Committee publication. Oxford: Blackwell Science, 441451.

Foucault M. (1982) The subject and power. Critical Inquiry 8: 777-795.

Habermas J. (1976) Legitimation crisis, London: Heinemann.

Hall MA, Cullen D and Slack T. (1989) Organisational elites recreating themselves: The gender structure of National Sports Organisations. Quest 41: 28-45.

Hannan C. (2006) Challenging the gender order. (accessed 1 November 2013). 
Hargreaves J. (2000) Heroines of sport : The politics of difference and identity, London ; New York: Routledge.

Henry I, Radzi W, Rich E, et al. (2004) Women, leadership and the Olympic Movement, Loughborough: Institute of Sport \& Leisure Policy, Loughborough University and the International Olympic Committee.

Henry I and Robinson L. (2010) Gender Equity and Leadership in Olympic Bodies, Loughborough: Centre for Olympic Studies and Research, Loughborough University and International Olympic Committee.

Hovden J. (2000) "Heavyweight" men and younger women? The gendering of selection processes in Norwegian sports organistions. NORA 8: 17-32.

Hovden J. (2006) The gender order as a policy issue in sport: A study of Norwegian Sport Organisations. Nordic Journal of Feminist and Gender Research 14: 41-53.

Hovden J. (2010) Female top leaders - prisoners of gender? The gendering of leadership discourses in Norwegian sports organizations. International Journal of Sport Policy and Politics 2: 189-203.

Huse M and Solberg AG. (2006) Gender-related boardroom dynamics: How Scandinavian women make and can make contributions on corporate boards. Women in Management Review 21: 113-130.

Inglis S. (1997) Roles of the board in amateur sport organisations. Journal of Sport Management 11: 160-176.

International Working Group on Women and Sport. (1994) Brighton Declaration on Women and Sport. (accessed 1 November 2013).

International Working Group on Women and Sport. (1998) Windhoek Call for Action. (accessed 1 November 2013).

International Working Group on Women and Sport. (2002) The Montreal Tool Kit.

International Working Group on Women and Sport. (2006a) Kumamoto Commitment to Collaboration. (accessed 1 November 2013).

International Working Group on Women and Sport. (2006b) Program 4th IWG World Conference on Women and Sport, Kumamoto: International Working Group on Women and Sport.

International Working Group on Women and Sport. (2006c) Workshop: Changing the culture of leadership in sport. (accessed 1 November 2013).

International Working Group on Women and Sport. (2012) Sydney Scoreboard. Available at: http://www.sydneyscoreboard.com/.

Kanter RM. (1977) Men and women of the corporation, New York: Basic Books.

Kvande E. (2007) Doing gender in flexible organisations, Bergen, Norway: Fagbokforlaget.

Lukes S. (1974) Power: A radical view, London: Macmillan.

McKay J. (1992) Why so few? Women executives in Australian Sport, Canberra: National Sports Research Centre.

McKay J. (1997) Managing gender: Affirmative action and organisational power in Australian, Canadian and New Zealand sport, Albany, NY: State University of New York Press.

Nielsen S and Huse M. (2010) The contribution of women on boards of directors: Going beyond the surface. Corporate governance: An international review 18: 136-148.

Pfister G and Radtke S. (2009) Sport, women and leadership: Results of a project on executives in German sports organisations. European Journal of Sport Science 9: 229243.

Radtke S. (2006) Interview study: Biographies of women in honorary executive positions in German sport. In: Doll-Tepper G, Pfister G and Radtke S (eds) Progress towards 
leadership: Biographies and career paths of male and female leaders in German Sport Organisations. Koln: Sportverlag Strauss, 71-148.

Schofield T and Goodwin S. (2005) Gender politics and public policy making: Prospects for advancing gender equality. Policy and society 24: 25-44.

Schull V, Shaw S and Kihl IA. (2013) If a woman came in...she would have been eaten up alive: Analyzing gendered political processes in the search for an athletic director. Gender and society 27: 56-81.

Shaw S. (2006) Gender suppression in New Zealand regional sports trusts. Women in Management Review 21: 554-566.

Shaw S and Hoeber L. (2003) "A strong man is direct and a direct woman is a bitch": Gendered discourses and their influence on employment roles in sport organisations. Journal of Sport Management 17: 347-375.

Shaw S and Penney D. (2003) Gender equity policies in national governing bodies: An oxymoron or a vehicle for change? European Sport Management Quarterly 3: 78-102.

Shaw S and Slack T. (2002) 'It's been like that for donkey's years': The construction of gender relations and the cultures of sports organisations. Culture, Sport, Society 5: 86-106.

Sibson R. (2010) "I was banging my head against a brick wall": Exclusionary power and the gendering of sport organisations. Journal of Sport Management 24: 379-399.

Singh V and Vinnicombe S. (2004) Why so few women directors in top UK boardrooms? Evidence and theoretical explanations. Corporate governance: An international review 12: 479-488.

Skirstad B. (2002) Shortage of females in local, national and international sport structures. Belgium Olympic and Interfederal Committees Colloquium "La femme et les structures sportives". Brussels.

Skirstad B. (2009) Gender policy and organisational change: A contextual approach. Sport Management Review 12: 202-216.

Terjesen S, Sealy R and Singh V. (2009) Women directors on corporate boards: A review and research agenda. Corporate governance: An international review 17: 320-337.

United Nations. (1945) Charter of the United Nations. (accessed 18 July 2011).

United Nations. (1948) Universal Declaration of Human Rights. (accessed 18 July 2011).

United Nations. (1979) Convention on the elimination of all forms of discrimination against women (accessed 18 July 2011).

United Nations. (1995) The Beijing Declaration and Platform for Action: Fourth United Nations World Conference on Women. (accessed 18 July 2011).

United Nations. (2011) UN Millennium Development Goals. Available at: http://www.un.org/millenniumgoals/.

United Nations Division for the Advancement of Women. (2007) Women 2000 and beyond: Women, gender equality and sport, New York: United Nations Division for the Advancement of Women.

United Nations Division for the Advancement of Women. (2008) Women 2000 and beyond: The role of men and boys in achieving gender equality (accessed 15 February 2012).

van der Walt N and Ingley C. (2003) Board dynamics and the influence of professional background, gender and ethnic diversity of directors. Corporate governance: An international review 11: 218-234.

West C and Fenstermaker S. (1995) Doing difference. Gender and society 9: 8-37.

West C and Zimmerman DH. (1987) Doing gender. Gender and society 1: 125-151.

White A and Brackenridge C. (1985) Who rules sport? Gender divisions in the power structure of British sports organisations from 1960. International Review for the Sociology of Sport 20: 95-106. 
World Health Organisation. (1986) The Ottawa Charter for Health Promotion. (accessed 18 July 2011).

Yin RK. (2009) Case study research: Design and methods, Thousand Oaks, CA: Sage Publications Inc. 